\title{
Las fuentes de acceso público a datos personales
}

\author{
The Sources of Public Access to Personal Data
}

FRANCISCO ALVARADO ÁVALOS

Abogado independiente

RESUMEN Las leyes sobre protección de datos personales usualmente contemplan excepciones al principio del consentimiento del titular de los datos. Una de las figuras más usadas en España y Latinoamérica son las fuentes de acceso público a datos personales. Sin embargo, su regulación debe ser detallada para que el libre acceso que permite a ciertos datos no se transforme en la regla general y conlleve una pérdida en la privacidad de las personas. Al comenzar una nueva discusión legislativa para cambiar la Ley I9.628, es pertinente realizar un análisis de esta figura de modo tal que los cambios que se propongan nos lleven a un mayor nivel de protección de los datos personales.

PALABRAS Clave Datos personales, consentimiento, excepciones al consentimiento, fuentes de acceso público, datos públicos.

ABSTRACT The data protection laws usually include exceptions to the principle of the consent from the data titular. One of the most used figures in Spain and Latin America are the sources of public access to personal data. However, its regulation must be detailed, that allows free access to certain data, does not become the general rule and lead us to a loss of privacy. At the beginning a new discussion to change the Law 19.628, it 
is important to do an analysis of this figure so that the proposed changes lead us to a higher level of protection of personal data.

KEYWORDS Personal data, consent, exceptions to consent, sources of public access, public data.

\section{INTRODUCCIÓN}

Los datos personales son definidos por el artículo 2 letra f) de la Ley I9.628 como «los relativos a cualquier información concerniente a personas naturales, identificadas o identificables». El uso de esta información constituye la base para un sinnúmero de negocios, como la publicidad o las páginas de información sobre riesgos crediticios.

Por regla general, quienes quieran realizar ciertas operaciones respecto a los datos personales, es decir, "realizar cualquier tratamiento que constituya cualquier operación o complejo de operaciones o procedimientos técnicos, de carácter automatizado o no, que permitan recolectar, almacenar, grabar, organizar, elaborar, seleccionar, extraer, confrontar, interconectar, disociar, comunicar, ceder, transferir, transmitir o cancelar datos de carácter personal, o utilizarlos en cualquier otra forma» ${ }^{\text {I }}$ deben necesariamente contar con el consentimiento del titular de los datos personales en cuestión.

Si bien nuestra legislación no define qué se entiende por consentimiento, la Directiva 95/46/CE de la Unión Europea lo define como «toda manifestación de voluntad, libre, específica e informada, mediante la que el interesado consienta el tratamiento de datos personales que le conciernan». ${ }^{2}$ Este requisito, consagrado en nuestra legislación, supone que cualquier tratamiento como los ya mencionados requiere previamente la autorización del titular de los datos, en atención a que éstos constituyen una parte de la vida privada de las personas, derecho fundamental que además encuentra consagración a nivel constitucional en el artículo I9 núm. 4 de nuestra Carta Fundamental. ${ }^{3}$

\footnotetext{
I. Ley 19.628, artículo 2 letra o).

2. Directiva 95/46/CE, artículo 2 letra h).

3. Inclusive algunos países consagran como derecho fundamental la protección de
} 
No obstante lo anterior, existen casos en los cuales se puede obviar dicho requisito mediante figuras consideradas en la propia legislación, cuyo objetivo primordial es flexibilizar el régimen de protección en atención a ciertos usos que el legislador consideraría pertinentes.

Una primera excepción lo constituye el tratamiento de datos personales realizado por personas jurídicas privadas, cuando éste sea realizado para fines propios, de tarificación, fines estadísticos y otros de beneficio general de sus afiliados, siempre para su uso exclusivo, impidiendo su comunicación a terceros. Otra excepción está contemplada en el artículo 20 de la Ley 19.628 respecto al tratamiento de datos personales realizado por organismos públicos. Esta excepción está limitada a que se trate de materias de su competencia, sometiéndose en lo demás a las reglas comunes establecidas en nuestra ley sobre protección de datos.

En tercer lugar, las fuentes de acceso público a datos personales son la última de las excepciones contempladas en nuestra ley. Éstas son bases de datos, públicas o privadas, cuyo acceso es libre o sujeto a una contraprestación, generalmente un pago previo.

Estas bases de datos se configuran, por lo general, de dos maneras. Una es estableciendo que ciertas bases de datos en particular serán de libre acceso, atendiendo más a la fuente que a los datos que la conforman; la otra, corresponde a determinar mediante la ley qué tipos de datos pueden ser de acceso libre, dándole mayor relevancia a ese aspecto que a los bancos que los contienen.

En cuanto a los efectos, estas bases de datos tienen como efecto principal el que los datos obtenidos de ellas pueden ser libremente utilizados para cualquier tratamiento de datos, pues no requieren obtener el consentimiento del titular de los datos y tampoco deben respetar una finalidad particular al momento de obtenerlos. Además, según lo establezca cada legislación en particular, podrán evitarse otras obligaciones que establece la ley, como la confidencialidad de los datos, la finalidad de su tratamiento, entre otras.

Podemos recalcar la gran importancia de una adecuada configuración legal de este tipo de bases de datos en cualquier ley sobre protección de

datos personales de manera independiente de la protección de la vida privada. Ejemplos son Argentina (artículo 43, inciso tercero), Brasil (artículo 5 núm. 7I), Colombia (artículo I 5), entre otros. 
datos, pues puede prestarse para usos abusivos y eludir los derechos de los titulares de los datos.

En este artículo analizaré las características principales de las fuentes de acceso público conforme el actual diseño de nuestra ley sobre protección de datos personales, cotejándolas además con las definiciones de algunas legislaciones comparadas. Finalmente, haré un breve estudio de las fuentes de acceso público en el anteproyecto presentado por el gobierno para modificar la Ley I9.628.

\section{LAS FUENTES DE ACCESO PÚBLICO EN LA LEGISLACIÓN COMPARADA}

Tanto en la ley española como en varias legislaciones latinoamericanas se contemplan excepciones al principio del consentimiento, desarrollando dos formas de permitir el libre acceso a datos personales. Por un lado, siguiendo el modelo español, existe la figura de la fuente de acceso público, como base de datos especial sobre la cual no será necesario obtener el consentimiento para su recogida y posterior tratamiento; mientras por el otro, sin importar la base de datos de que se trate, algunas leyes han establecido que ciertos datos tendrán el carácter de públicos o de acceso irrestricto, permitiendo su libre recogida y tratamiento.

Partiremos analizando el uso de esta figura en las leyes de protección de datos europeas, para posteriormente revisarlas en América Latina.

\section{EUROPA}

La legislación base en Europa para la regulación de la protección de los datos personales es la Directiva 95/46/CE. Este cuerpo legal marca la pauta de las directrices que deben cumplir las leyes de trasposición que cada país adopte para el cumplimiento de las normas comunitarias.

En lo que respecta a las fuentes de acceso público, la Directiva no las menciona en ninguno de sus artículos. La mención más cercana a este tipo de registro se encuentra en la regulación relativa al flujo transfronterizo de datos personales. El artículo 25 de la mencionada directiva establece los principios básicos bajo los cuales se ampara una legítima transferencia internacional de datos personales, siendo la regla principal para permitir este movimiento que el país destinatario de los datos personales garantice un nivel adecuado de protección. Luego, el artículo 26 
señala, como excepciones a ello, que la transferencia tenga lugar desde un registro público que, en virtud de disposiciones legislativas o reglamentarias, esté concebido para facilitar información al público y esté abierto a consulta general, bajo las condiciones establecidas por la ley. ${ }^{4}$

El modelo español es el más replicado a lo largo de Latinoamérica y uno de los que se tienen siempre a la vista cuando se trata de modificar nuestra ley de protección de datos, aunque con matices. En un primer momento, por medio de la Ley Orgánica de Regulación del Tratamiento Automatizado de Datos de Carácter Personal (LORTAD), se consideró las fuentes de acceso público, sin definirlas, como excepciones al consentimiento del titular de datos personales. El artículo 6 de la LORTAD se refería escuetamente a las fuentes accesibles al público, señalando que al recoger datos personales desde ellas, el consentimiento no será necesario. No existía control sobre qué era una fuente de acceso público; era un concepto abierto y que dejaba en alto grado de incertidumbre la verdadera eficacia de los derechos de los titulares de los datos.

Posteriormente, con la necesidad de adaptar su legislación interna a la Directiva, España dictó en 1999 la Ley Orgánica de Protección de Datos de Carácter Personal (LOPD). En un cambio sustancial, las fuentes de acceso público pasaron de una pequeña oración con una interpretación abierta, a un concepto cerrado; la LOPD define en su artículo 3 letra j) las fuentes de acceso público como «aquellos ficheros cuya consulta puede ser realizada, por cualquier persona, no impedida por una norma limitativa o sin más exigencia que, en su caso, el abono de una contraprestación». La definición es amplia y genérica respecto a las bases de datos que podrían considerarse como fuentes de acceso público, no obstante esto se ve limitado por el mismo artículo, pues establece un catá-

4. Sobre este punto, los registros públicos se refieren a los registros llevados por la administración pública, constituyendo un supuesto de inaplicabilidad parcial de la Directiva. Como recalca Heredero, el considerando $58 .^{\circ}$ de la Directiva precisa, además, que no se incluyen en esta excepción todos los datos contenidos en tal registro, y que la transferencia sólo debiese efectuarse a petición de las personas que acrediten un interés legítimo sobre dichos datos personales para mantener una proporcionalidad entre la excepción para la transferencia de los datos y la protección debida a los titulares de ellos. Valga mencionar aquí que los países europeos han recogido estas excepciones, aunque en algunos casos bajo la supervisión de la autoridad de control correspondiente (como en el Reino Unido o Grecia) (Heredero, I997: I92 y ss.). 
logo taxativo de bancos de datos que pueden considerarse como fuentes de acceso público, sobre las cuales no puede agregarse ningún otro. Éstas son: el censo promocional; los repertorios telefónicos en los términos previstos por su normativa específica; las listas de personas pertenecientes a grupos de profesionales que contengan únicamente los datos de nombre, título, profesión, actividad, grado académico, dirección e indicación de su pertenencia al grupo; los diarios y boletines oficiales; y los medios de comunicación. Sobre éstos no se considerará ninguna otra base de datos, ${ }^{5}$ lo que ha sido ratificado tanto por la Agencia Española de Protección de Datos como por el Tribunal Supremo Español. ${ }^{6}$

Otro país europeo que contempla las fuentes de acceso público es el Reino Unido, pero no como excepción al consentimiento. La Data Protection Act de 1998 establece las fuentes de acceso público, pero como excepción a ciertos principios de esa ley. Así, la Parte IV sección 34 las contempla, y exime del deber de otorgar información al momento de recoger los datos, del respeto a los principios contenidos en la Parte I sección $4,{ }^{7}$ de lo dispuesto en la sección I4 números I al $3,{ }^{8}$ y de la

5. La Agencia de Protección de Datos Personales Española ha rechazado que otro tipo de bases de datos puedan considerarse como fuentes de acceso público, pese a que en los hechos son de libre acceso, por lo que ha sancionado su utilización. Así se ha pronunciado en las resoluciones 862/2008, I370/2009, I92/2009, 500/2009 y 544/2009, siempre destacando el carácter taxativo del catálogo.

6. El Tribunal Supremo Español se ha pronunciado ratificando el carácter taxativo de este listado, pero ha realzado que dicha disposición se contradice con la Directiva Europea 95/46/CE, pues ésta normativa no contendría tales disposiciones y «rompe la armonización total perseguida por la norma de derecho comunitario, al establecer una lista cerrada y exhaustiva de fuentes accesibles al público, siendo plausible que otros Estados miembros puedan considerar como tales otro tipo de ficheros", pero respecto al flujo transfronterizo de datos de carácter personal a través de la Comunidad Europea. Véase sentencia del Tribunal Supremo Español de fecha 8 de febrero de 2012.

7. La mentada sección hace una vinculación directa con el Esquema I, el cual en su primera parte señala los principios básicos del tratamiento de datos, como son el tratamiento leal dentro de la ley, la finalidad para la cual se recogen los datos, adecuación y pertinencia de los datos utilizados para el fin buscado, calidad de los datos, seguridad, entre otros.

8. La sección I4 se refiere a los derechos que le corresponden a los titulares de datos personales; éstos son la modificación, el bloqueo o la cancelación de los datos personales. Sin embargo, mantiene aplicables las disposiciones de la misma sección, que se 
obligación de mantener reserva de los datos. La ley inglesa no incorpora ninguna definición de qué se entiende como fuente de acceso público; sólo señala como excepción a la información disponible al público, sin especificar su origen, por lo que también tendría semejanzas con la otra hipótesis de datos accesibles al público.

A estos casos debemos sumarles aquellos países que, si bien no establecen fuentes de acceso público a datos personales, tienen otras excepciones al principio del consentimiento, aunque con matices distintivos. Uno de ellos es Francia y su Ley de Informática y Libertades 78/I7, que permite ciertas excepciones al consentimiento. Una es el hecho de que se puedan tratar datos sensibles sin necesidad de consentimiento del titular de los datos, cuando éste los haya hecho públicos. ${ }^{9}$ Otra forma es la posibilidad de transmitir datos de carácter personal hacia un Estado que no posea el mismo nivel de protección, cuando los datos provengan de registros públicos que, con arreglo a la normativa vigente, esté disponible para consulta del público o de toda persona que justifique un interés legítimo.

También Portugal y su Ley 67/98, cuyo artículo 20 señala como excepción a que la transferencia internacional de datos personales se haga sólo a países que cuenten con un nivel de protección equivalente, los casos en que los datos se obtuviesen de registros públicos que tienen por objetivo informar al público y se encuentre abierto a consulta general o por persona que demuestre un interés legítimo; sin embargo, no delimita qué se entenderá por registro público, lo que puede llevar a confusiones.

\section{ARGENTINA}

La Ley 25.326 sobre protección de los datos personales, contempla esta figura en su artículo 5 número 2 letra a), señalando que no será necesario el consentimiento para el tratamiento de datos personales cuando éstos provengan de fuentes de acceso público irrestricto. Esta ley no con-

refieren a compensaciones por daños sufridos debido al tratamiento de datos personales que no han cumplido con los parámetros establecidos por la ley, lo que además permite la modificación, bloqueo o eliminación de los datos personales utilizados en dicho tratamiento lesivo.

9. Artículo 8 sección II número 4 . 
templa una definición legal, según Puccinelli (2004: 207-208), por los posibles conflictos interpretativos que ocasionaría.

Palazzi (2004: 49) da a entender en este punto que lo relevante es el dato obtenido, más que la fuente que lo contiene. Así, distingue:

- datos del dominio público, al ser conocidos por todos;

- datos que son públicos porque una norma así lo dispone; y

- datos que, aunque no son públicos, devienen en tales por la conducta expresa de sus titulares.

Esto no ayuda a esclarecer qué son las fuentes accesibles al público en la legislación argentina. No obstante, queda claro que lo dispuesto por la Ley 25.326 es un catálogo abierto que finalmente otorga libertad de interpretación sobre qué soportes quedarían dentro de esta figura, y cuáles no.

Respecto a las bases de datos mantenidas por un organismo público, si bien se tendría acceso libre sobre su información, Gils (2001: 82-83) distingue entre la mera consulta de algunos datos de tal registro y el acceso a la base de datos completa. No existe una regulación general sobre el punto, por lo que se aplicarían las disposiciones específicas que regulen cada registro; no obstante, sólo podría concederse acceso cuando exista causa legítima y razones de interés público.

\section{COLOMBIA}

Colombia sigue un camino similar al argentino, pues en su Ley Estatutaria I.58 I señala que no se requerirá la autorización del titular de los datos para su tratamiento cuando los datos sean de naturaleza pública. ${ }^{\text {ㅇ }}$

Esta frase no abarca lo que pudiese incluir una fuente accesible al público, pues éstas además de datos públicos (nombres, teléfono, dirección, etc.), pueden incluir datos que sean privados, haciendo falta un mayor detalle para darle adecuada forma a la excepción establecida. No existe otra mención relativa a esta materia en la ley colombiana.

Io. Artículo 8 sección II número 4. 


\section{COSTA RICA}

En la regulación costarricense, el artículo 5 número 2 letra b) señala que no será necesaria la autorización del titular cuando se trate de datos personales de acceso irrestricto, obtenidos de fuentes de acceso público general. Por su parte, los datos personales de acceso irrestricto conforme al artículo 3 letra c), son los contenidos en bases de datos públicas de acceso general, según dispongan leyes especiales y de conformidad con la finalidad para la cual estos datos fueron recabados. Finalmente, no serán datos personales de acceso irrestricto: la dirección exacta de la residencia, la fotografía, los números de teléfono privados y otros de igual naturaleza cuyo tratamiento pueda afectar los derechos y los intereses de la persona titular, según el artículo 9 número 3 inciso segundo.

\section{MÉXICO}

Es el caso de México, la ley aprobada en el 20 io define las fuentes de acceso público de manera casi idéntica a la ley española ${ }^{\mathrm{II}} \mathrm{y}$, complementándola con su reglamento, en su artículo 7 establece como fuentes de acceso público exclusivamente a los directorios telefónicos, diarios, gacetas o boletines oficiales; los medios de comunicación social, y los medios remotos o locales de comunicación electrónica, óptica u de otra tecnología, siempre que el sitio donde se encuentren los datos esté concebido para facilitar información al público y esté abierto a la consulta general. Además, la información debe tener siempre una procedencia lícita.

\section{PARAGUAY}

La Ley I.682 reglamenta la información de carácter privado. En su breve articulado no existe mención a las fuentes de acceso público; sin embargo, el artículo 2 de esta ley dispone el libre acceso a los datos asentados en registros llevados por organismos públicos. Además, tras la reforma de la Ley I.969, el artículo 5 permite la difusión o publicación de los da-

I I. Artículo 3 de la Ley Federal de Protección de Datos Personales en posesión de los particulares. Fuente de acceso público: Aquellas bases de datos cuya consulta puede ser realizada por cualquier persona, sin más requisito que, en su caso, el pago de una contraprestación, de conformidad con lo señalado por el Reglamento de esta Ley. 
tos sobre situación patrimonial o cumplimiento de obligaciones comerciales y financieras, si tales informaciones constan en fuentes públicas de información. Sin embargo, dentro del texto reformado no se explicita qué se entenderá por fuentes públicas de información.

PERÚ

La Ley 29.733 de Perú utiliza una definición similar a las anteriores, entendiendo como fuentes de acceso público aquellos «bancos de datos personales de administración pública o privada, que pueden ser consultados por cualquier persona, previo abono de la contraprestación correspondiente, de ser el caso». ${ }^{\mathrm{I}}$

El reglamento de esta ley, en su artículo 22 establece cuáles son las fuentes de acceso público:

- Los medios de comunicación electrónica, óptica y de otra tecnología, siempre que el lugar en el que se encuentren los datos personales esté concebido para facilitar información al público y esté abierto a la consulta general.

- Las guías telefónicas, independientemente del soporte en el que estén a disposición y en los términos de su regulación específica.

- Los diarios y revistas independientemente del soporte en el que estén a disposición y en los términos de su regulación específica.

- Los medios de comunicación social.

- Las listas de personas pertenecientes a grupos profesionales que contengan únicamente los datos de nombre, título, profesión, actividad, grado académico, dirección postal, número telefónico, número de fax, dirección de correo electrónico y aquellos que establezcan su pertenencia al grupo. En el caso de colegios profesionales, podrán indicarse además los siguientes datos de sus miembros: número de colegiatura, fecha de incorporación y situación gremial en relación al ejercicio profesional.

- Los repertorios de jurisprudencia, debidamente anonimizados.

I2. Ley 29.733, artículo 2 número 9. 
- Los registros públicos administrados por la Superintendencia Nacional de Registros Públicos, así como todo otro registro o banco de datos calificado como público conforme a ley.

- Las entidades de la Administración Pública, en relación a la información que deba ser entregada en aplicación de la Ley 27.806, Ley de Transparencia y Acceso a la Información Pública. El reglamento hace la salvedad de que no todo dato en posesión de las entidades sometidas a la ley de transparencia será considerado información pública, si no que su acceso se permitirá atendiendo a las circunstancias particulares de cada solicitud.

\section{URUGUAY}

El año 2008, Uruguay dictó una ley general de protección de datos, buscando acercarse a los niveles de protección otorgados en Europa. La Ley I 8.33 I contempla dentro de su articulado a las fuentes de acceso público, definiéndolas como «aquellas bases de datos cuya consulta puede ser realizada por cualquier persona, no impedida por una norma limitativa o sin más exigencia que, en su caso, el abono de una contraprestación». ${ }^{\text {13 }}$

No obstante una acertada definición legal, posterior, en el artículo 9 inciso tercero señala que no se requerirá consentimiento cuando los datos provengan de fuentes accesibles al público, como registros o publicaciones en medios masivos de comunicación. Esta parte del artículo $9^{\mathrm{I} 4}$ da cuenta de un concepto abierto de fuente de acceso público a datos personales, el cual no limita la naturaleza de los datos que podrían recogerse, ni las bases de datos que serían de este tipo.

I3. El artículo 4 letra i) de la Ley i 8.33 I las define como «aquellas bases de datos cuya consulta puede ser realizada por cualquier persona, no impedida por una norma limitativa o sin más exigencia que, en su caso, el abono de una contraprestación».

I4. Artículo 9. «Principio del previo consentimiento informado. El tratamiento de datos personales es lícito cuando el titular hubiere prestado su consentimiento libre, previo, expreso e informado, el que deberá documentarse. [...] No será necesario el previo consentimiento cuando: a) Los datos provengan de fuentes accesibles públicas de información, tales como registros o publicaciones en medios masivos de comunicación [...]». 


\section{LAS FUENTES DE ACCESO PÚBLICO EN LA LEY 19.628}

\section{CONCEPTO}

Nuestra ley sobre protección de datos contempla las fuentes de acceso público en su artículo 2 letra i), al definirlas como «los registros o recopilaciones de datos personales, públicos o privados, de acceso no restringido o reservado a los solicitantes».

El amplio carácter de esta definición debe complementarse con lo dispuesto en el artículo 4 inciso quinto del mismo cuerpo legal, el cual establece el marco de acción de la excepción. Así, se permite el tratamiento de datos personales que provengan de fuentes acceso público cuando éstos:

- sean de carácter económico, financiero, bancario o comercial;

- se contengan en listados relativos a una categoría de personas que se limiten a indicar antecedentes tales como la pertenencia del individuo a ese grupo, su profesión o actividad, sus título educativos, dirección o fecha de nacimiento;

- o sean necesarios para comunicaciones comerciales de respuesta directa o comercialización o venta directa de bienes o servicios.

De esta forma se conformaría una hipótesis de aplicación taxativa y alternativa, limitada en cuanto a la información contenida, pero abierta en cuanto a qué tipo de base de datos puede considerarse fuente accesible al público (Jervis, 2005: I 22). Esto dista de lo establecido en España, México o Perú, siendo este aspecto de la Ley I9.628 uno de los más criticados, por cuanto la laxitud de la definición permite que cualquier banco de datos pueda considerarse como fuente de acceso público, con las ventajas que ello conlleva para quienes, por ejemplo, hacen negocios en torno al tratamiento de esta información.

\section{ALCANCE}

En cuanto al alcance del concepto, discute la doctrina si se debe atener a una cuestión normativa o más bien de hecho. Por un lado, Cerda sostiene que todas las bases de datos serían de acceso restringido salvo que una ley les otorgara el carácter de público, pues esta interpretación se 
aviene más con el espíritu de la ley, las fuentes de acceso público constituyen una excepción a la regla general debiendo interpretarse restrictivamente, y aun existiendo disposiciones legales que declaran reservada cierta información, su propósito no ha sido declarar públicas las demás bases de datos (Cerda, 2003: 70). Por otro lado, Jijena defiende que al consagrar la legislación chilena ciertas bases de datos como reservadas (como el secreto bancario o el secreto tributario), las demás bases de datos existentes son por defecto de carácter público mientras no haya norma especial que diga lo contrario.

A mi parecer, respecto a los bancos de datos que lo conformarían parece necesario distinguir entre bases de datos mantenidas por particulares y las que poseen los organismos públicos. Sobre las primeras, al no existir límite legal respecto a qué bases de datos pueden ser de libre acceso público, dependerá del responsable de datos determinar su naturaleza, adaptándose la base de datos a las características propias ya vistas. Así, mientras se permita el libre acceso, la base de datos podrá ser considerada fuente de acceso público, salvo que una ley establezca la reserva o secreto de determinada información (dentro de las hipótesis de aplicación mencionadas).

En lo referente a bancos de datos cuyo responsable es un organismo público, el conflicto surge cuando la ley no expresa ni su privacidad, confidencialidad o secreto, ni su publicidad o transparencia en el tratamiento de la información contenida en un registro. La Ley 20.285 sobre Acceso a la Información Pública, en su artículo 2 I señala las causales por las que se podrá denegar el acceso a la información, declarando en su número 2 cuando su publicidad, comunicación o conocimiento afecte los derechos de las personas destacando, junto a otros, la esfera de su vida privada. Rajevic indica que se ha fallado analizando el daño que provocaría la decisión de publicidad y el interés público envuelto en la reclamación deducida para el acceso a la información, que «consisten en realizar un balance entre el interés de retener la información y el interés de divulgarla, para determinar si el beneficio público resultante de conocer la información solicitada es mayor que el daño que podría ocasionar su revelación» (Rajevic, 20I I: I 55 ). Considero que las bases de datos en poder de organismos públicos, cuya publicidad no sea establecida por ley, debiese ser información reservada, atendido que la regla general debiese ser la privacidad de los datos personales 
que la componen y lo dispuesto en el mismo artículo 2 I número 2 de la Ley 20.285. En aquellos casos en que no existe norma específica será, en definitiva, el Consejo para la Transparencia quien dirimirá el conflicto.

En el mismo sentido argumenta Jijena, para quien las bases de datos de los órganos de la administración no serían de libre acceso, lo cual a su juicio sería inconstitucional e ilegal. Este autor señala que esto deberá ser considerado por el Consejo para la Transparencia mediante un «test de transparencia», lo cual significa «balancear el principio de proporcionalidad entre el interés que pueda existir para dar publicidad a una información administrativa determinada con el interés en mantenerla reservada» (Jijena, 20I4: 7I).

\section{EFECTOS}

El principal efecto de las fuentes accesibles al público es que el tratamiento de datos personales está exento de requerir el consentimiento del titular de datos personales, lo cual disminuye los costos y permite cualquier tipo de tratamiento, inclusive su transferencia a terceros sin necesidad de información alguna al titular de los datos. Otros efectos derivados de esta excepción al consentimiento son:

- No verse sujetos al principio de finalidad de los tratamientos de datos. ${ }^{15}$

- Quienes trabajen con datos personales no tendrán el deber de guardar reserva de los mismos. ${ }^{16}$.

- También pueden tener un efecto sobre los derechos de las personas. Así, conforme al artículo I2, el derecho a exigir informaciones del responsable del banco de datos respecto a un tratamiento de información, no sufre detrimento legal alguno por haber sido recogido desde fuentes de acceso público; del mismo modo respecto al derecho de modificación, sus requisitos y efectos se mantienen inalterados. Un grado de debilidad se observa en el derecho de eliminación o cancelación, por cuanto éste es exigible cuando su

\footnotetext{
I 5. Artículo 9 inciso primero.

I6. Artículo 7 de la Ley I9.628.
} 
tratamiento carezca de fundamento legal, estuvieren caducos, los datos hayan sido proporcionados voluntariamente por el titular de los datos personales, o se usen para comunicaciones comerciales y no se desee continuar figurando en tal registro, definitiva o temporalmente; si los datos fueron obtenidos desde fuentes accesibles al público pero no se encuadran en los demás casos de cancelación ya dichos, éstos podrán seguir siendo tratados, quitándole algo de fuerza al derecho de cancelación que le corresponde a todos los titulares de datos personales.

\section{CRÍTICAS}

Las fuentes accesibles al público han sido uno de los aspectos más criticados de nuestra ley sobre protección de datos personales. Se ha dicho que uno de sus defectos sustanciales en esta materia es que radica en el titular del banco de datos la facultad de dejar abierto o no el acceso público al registro, con el consecuente riesgo de fraude a la ley y los derechos del titular de los datos (Arrieta, 2009), pues no existiendo un catálogo de bases de datos que puedan ser fuentes de acceso público, para el caso de que estos registros pertenezcan a privados, serán ellos quienes decidirán si son de libre acceso o no.

Se ha señalado también que al dar una amplia e indeterminada definición, deja un régimen de excepciones amplio para vulnerar el principio del consentimiento (Anguita, 2007: 559); en el mismo sentido, el Jijena critica la incorporación de las fuentes accesibles al público «en términos amplísimos», lo que permitiría que, legalmente, la excepción pase a ser la regla general. El mismo autor señala que algunas fuentes de información son reservadas o confidenciales por estricta disposición legal, como los datos relativos al secreto tributario, estadístico o de filiación política, considerando que la regla general respecto a las distintas bases de datos es que sean de libre acceso (Jijena, 20I0: 4I7).

\section{EL ANTEPROYECTO DE REFORMA}

El Ministerio de Economía, Fomento y Turismo presentó en el año 2014 a consulta pública un nuevo anteproyecto de reforma a la ley sobre protección de datos personales, buscando poner énfasis sobre los derechos 
de los titulares de datos y protegerlos efectivamente, haciéndose eco de las críticas transversales existentes sobre nuestra actual legislación. ${ }^{17}$

El anteproyecto puesto en consulta consta de nueve títulos tentativos. En el primero de ellos se desarrollan las disposiciones generales de la ley: su objeto, ámbito de aplicación y definiciones. El título segundo establece los principios que regirían el tratamiento y recogida de datos de carácter personal, estos son: legitimidad (consentimiento), proporcionalidad, calidad, transparencia, responsabilidad y seguridad. En el título tercero se fijan los derechos que posee el titular de los datos, los derechos que tiene sobre éstos y la forma de ejercerlos, junto con su irrenunciabilidad. El título cuarto lleva por nombre «Otras disposiciones» y en él se fijan responsabilidades y cargas para los encargados y responsables del tratamiento de información, como la confidencialidad, códigos de conducta y regulación de la cesión de datos personales. Los datos especialmente protegidos se hallan en el título quinto, determinando qué información tendría éste carácter, dándoles un mayor nivel de protección sobre ellos y reglas más estrictas sobre su tratamiento. En el título sexto se regula la transferencia internacional de datos personales. El título séptimo ordena la creación y administración de un Registro Nacional de Bases de Datos, los contenidos de este registro y la comunicación de esta información. El título octavo es el que crea un Consejo de Protección de Datos, la autoridad de control encargada de "promover y garantizar el derecho de las personas naturales de proteger y controlar los datos personales que le conciernen, fiscalizar el cumplimiento de las normas, generales y especiales, sobre el tratamiento de datos personales» (Ministerio de Economía, Fomento y Turismo, 2014: 27); fija además su estructura, objeto, facultades y funcionamiento. Finalmente, el título noveno desarrolla un catálogo de infracciones y sanciones a la ley de protección de datos personales, dividiéndolas en leves, graves y muy graves; las multas a las que se exponen quienes vulneren esta normativa $\mathrm{y}$ algunos aspectos procesales.

I7. Disponible en http://www.participacionciudadana.economia.gob.cl/consultas-ciudadanas-virtuales/ante-proyecto-de-ley-proteccion-de-las-personas-del-tratamiento-de 


\section{REGULACIÓN PROPUESTA}

En lo relativo a las fuentes de acceso público, se propone como nueva definición de las fuentes de acceso público: «base de datos cuyo acceso o consulta puede ser efectuado legítimamente por cualquier persona, sin más exigencia que, en su caso, el abono de una contraprestación» (Ministerio de Economía, Fomento y Turismo, 20I4: 4). Como ámbito de aplicación de las fuentes de acceso público, el proyecto establece que «no se requerirá el consentimiento del titular cuando los datos personales provengan de una fuente accesible al público y su tratamiento sea necesario para la satisfacción del interés legítimo perseguido por el responsable o por el tercero a quien los datos se hayan comunicado, siempre que no se vulneren los derechos fundamentales del titular» (Ministerio de Economía, Fomento y Turismo, 2014: 7).

Respecto a la definición propuesta, no existe mayor innovación, toma la definición consagrada en la legislación española y la transcribe casi idénticamente, como muchas otras leyes latinoamericanas que ya vimos.

La diferencia existente entre esa ley y el anteproyecto propuesto tiene que ver con el ámbito de aplicación de esta excepción. La legislación española además de su definición, posee un catálogo cerrado de bancos de datos susceptibles de ser considerados como fuentes accesibles al público; en cambio, la definición planteada en el anteproyecto no hace esta distinción, mantiene un catálogo abierto tal como está establecido en la actual Ley 19.628. El mayor problema que genera este punto es la incertidumbre respecto a qué bases de datos son o podrían ser fuentes de acceso público; al dejar un concepto abierto nuevamente se entra en la discusión si esta categoría responde a una situación de hecho o a una determinación normativa, con el riesgo que ello podría conllevar para el titular de esos datos, al permitirse tratamientos sin su consentimiento.

A ello debe agregarse que la Ley I9.628 en su artículo 4 establece qué tipos de datos podían formar parte de una fuente accesible al público, limitándola a datos de carácter económico, bancario, financiero o comercial; que los datos se contengan en listados relativos a una categoría de personas que se limiten a indicar antecedentes tales como la pertenencia del individuo a ese grupo, su profesión o actividad, sus títulos educativos, dirección o fecha de nacimiento; o sean necesarios para comunicaciones comerciales de respuesta directa o comercialización o 
venta directa de bienes o servicios. En cambio, la regulación propuesta no incluye ninguna limitación tan explícita respecto a las fuentes de acceso público. ${ }^{18}$

También, respecto a la cesión de datos personales, no será necesario obtener el consentimiento del titular de éstos cuando provengan de una fuente accesible al público (Ministerio de Economía, Fomento y Turismo, 20I4: I 5).

Respecto a otros efectos, en lo relativo a la confidencialidad el proyecto en su pregunta 38 establece: «Los responsables y encargados de tratamiento, así como cualquier persona que participe a cualquier título en operaciones de tratamiento de datos personales, están obligados a guardar secreto sobre los mismos, cuando provengan o hayan sido recolectados de fuentes no accesibles al público, como asimismo sobre los demás datos y antecedentes relacionados con las bases de datos» (Ministerio de Economía, Fomento y Turismo, 20I4: I4); esto guarda relación con lo que actualmente propone la Ley r9.628 en su artículo $7 \cdot{ }^{\text {19 }}$ Así, interpretándolo en sentido contrario, la información que sea recolectada desde fuentes accesibles al público no está sujeta a la confidencialidad establecida en la ley. Esto responde a que, dado el carácter público de dicha información, no tiene sentido generar la carga de la confidencialidad o reserva a quienes trabajen con este tipo de datos.

Respecto al tratamiento de datos relativos a información de carácter económico, financiero, bancario o comercial, el proyecto señala: "Quienes se dediquen a la prestación de servicios de información sobre el cumplimiento o incumplimiento de las obligaciones de carácter económico, financiero, bancario o comercial sólo podrán tratar datos personales obtenidos de fuentes accesible a público o procedentes de información proporcionada directamente por el titular u obtenida con su consentimiento» (Ministerio de Economía, Fomento y Turismo, 2014: I9). En

I 8. Sí incluye limitaciones según el tipo de datos personales de que se trate; por ejemplo, respecto a los datos personales sensibles.

I9. Artículo 7. «Las personas que trabajan en el tratamiento de datos personales, tanto en organismos públicos como privados, están obligadas a guardar secreto sobre los mismos, cuando provengan o hayan sido recolectados de fuentes no accesibles al público, como asimismo sobre los demás datos y antecedentes relacionados con el banco de datos, obligación que no cesa por haber terminado sus actividades en ese campo.» 
la actual Ley 19.628 se permite la comunicación de información que «conste en letras de cambio y pagarés protestados; cheques protestados por falta de fondos, por haber sido girados contra cuenta corriente cerrada o por otra causa; como asimismo el incumplimiento de obligaciones derivadas de mutuos hipotecarios y de préstamos o créditos de bancos, sociedades financieras, administradoras de mutuos hipotecarios, cooperativas de ahorros y créditos, organismos públicos y empresas del Estado sometidas a la legislación común, y de sociedades administradoras de créditos otorgados para compras en casas comerciales». Esta diferencia restringe las fuentes desde los cuales se podrá obtener información para comunicarla a terceros, cambiando la situación que actualmente rige en nuestro país, pudiendo obstaculizar el desarrollo de la industria dedicada a vender este tipo de información, al limitar las bases de datos desde donde podrían obtener datos personales. Seguramente será uno de los puntos más resistidos durante la tramitación de la ley pues toca uno de los aspectos más importantes para los sectores que trabajan en torno al tratamiento de datos personales, teniendo además en consideración que sobre este punto se discuten recursos de protección ante los tribunales de justicia, ${ }^{20}$ alegándose la procedencia de la publicación de datos de carácter económico, financiero, bancario o comercial (casi siempre se trata de la publicación de morosidades) y la legalidad de dicha publicación, argumentándose, entre otras cosas, que las bases de datos desde las cuales provienen corresponden a fuentes accesibles al público. No obstante, se mantiene cierto riesgo al no delimitar cuáles serán los bancos de datos que podrán ser fuentes accesibles al público.

Una última mención respecto a esto, aunque parezca indirecta, corresponde a lo propuesto como regulación para el tratamiento de datos relativos a menores de edad. La pregunta 47 del anteproyecto señala: «Se prohíbe el tratamiento de datos personales en bases de datos de titularidad privada de niños y niñas, salvo aquellos que sean de naturaleza pública, lo autorice la ley o el consentimiento haya sido otorgado en forma expresa y por escrito por su representante legal».

El punto polémico de este tentativo artículo tiene que ver con que son datos de «naturaleza pública». Dicho concepto no se encuentra dentro

20. Por ejemplo, las causas roles 2568-2007, 6I4I-2007, 6474-2008, 5922-20II, 697I-20I 2, 6777-20I 2 de la Corte Suprema. 
de las definiciones que propone el anteproyecto, quedando una incógnita al respecto, pues no se sabe si se refiere a una categoría especial de datos o a datos que pueden estar contenidos en alguna fuente de acceso público, lo cual se agrava en consideración de que se trata de datos de menores de edad, por lo que las restricciones respecto a su información deberían ser tratadas con la mayor rigurosidad.

\section{CONCLUSIONES}

Tras toda la normativa analizada, queda la sensación que la reforma anunciada, al menos en la forma actual y respecto a las fuentes de acceso público, queda en deuda.

Se propone una definición más rigurosa respecto de las fuentes de acceso público, pero como vimos esto por sí solo no es suficiente para darle el limitado alcance que, como excepción al principio general del consentimiento, debe tener. Para ello es fundamental tener claridad respecto a cuáles serán las bases de datos que se tendrán como fuentes de acceso público y las razones de por qué se permitirá esto. En este punto valdría más seguir el modelo español considerando la aplicación de un catálogo cerrado de bancos de datos que puedan considerarse fuentes de acceso público a datos personales, de modo tal que la excepción quede limitada y que el consentimiento por parte del titular de los datos mantenga su fuerza de regla general. ${ }^{21}$

La alternativa a esto, pensando siempre en mantener ciertos límites sobre esta figura, es establecer qué tipos de datos, más allá de la base que los contenga, pudiesen considerarse como de libre tratamiento. Así, los datos de carácter económico, bancario o comercial podrían tener esta denominación debido a su importancia para el funcionamiento normal del mercado, mientras que otros no expresamente exceptuados mantendrían su carácter de reservados salvo el consentimiento del titular, siguiendo así un modelo similar a lo dicho por Palazzi respecto a la legislación argentina, donde al no definir ni entregar un catálogo de fuentes de acceso público, se centra en los datos obtenidos para determinar su uso libre (Palazzi, 2004: 46-48).

2I. Incluso se ha sugerido que las fuentes accesibles al público sean determinadas sólo por ley, quedando por defecto todas las demás bases de datos con un acceso más restringido. 
No reparar esta omisión en el proyecto actual podría perpetuar la situación vigente bajo la Ley I9.628, dejando en incertidumbre qué bases de datos serían fuentes de acceso público y entregando una norma que flexibilice el tratamiento de datos personales, dificultando el ejercicio de los derechos por parte de sus titulares.

\section{REFERENCIAS}

Anguita, Pedro (2007). La protección de datos personales y el derecho a la vida privada. Santiago: Jurídica.

Arrieta, Raúl (2009). Chile y la protección de datos personales: Compromisos internacionales. En Varios autores, Chile y la protección de datos personales: ¿están en crisis nuestros derechos fundamentales?. Santiago: Ediciones Universidad Diego Portales.

CERDA, Alberto (2003). La autoridad de control en la legislación sobre protección frente al tratamiento de datos personales. Tesis para optar al grado de Magíster en Derecho. Santiago: Facultad de Derecho, Universidad de Chile.

GiLs, Alejandra (200I). Régimen legal de las bases de datos y habeas data. Buenos Aires: La Ley.

Heredero, Manuel (I997). La Directiva Comunitaria de Protección de los Datos de Carácter Personal. Pamplona: Editorial Aranzadi.

Jervis, Paula (2005). "Categorías de datos reconocidas en la Ley I9.628». Revista Chilena de Derecho Informático, 6: I I I-I45.

Jijena, Renato (20I0). "Actualidad de la protección de datos personales en América Latina. El caso de Chile». En Memoria del XIV Congreso Iberoamericano de Derecho e Informática, Monterrey. Disponible en $<$ http://biblio.juridicas.unam.mx/libros/6/2940/27.pdf>.

-. (2014). «Tratamiento de datos personales en el Estado y acceso a la información pública». Revista Chilena de Derecho y Tecnología, 2 (2): 49-94.

Ministerio de ECOnomía, Fomento y Turismo (20I4). Anteproyecto de Ley Protección de las Personas del Tratamiento de Datos Personales. Disponible en <http://www.participacionciudadana.economia.gob.cl/consultas-ciudadanas-virtuales/ ante-proyecto-de-ley-proteccion-de-las-personas-del-tratamiento-de>. Palazzi, Pablo (2004). La protección de los datos personales en la Ar- 
gentina: Ley 25.326 de protección de datos personales y habeas data comentada y anotada con jurisprudencia. Buenos Aires: Errepar.

Puccinelli, Oscar (2004). Protección de datos de carácter personal. Buenos Aires: Astrea.

Rajevic, Enrique (20II). "Protección de datos y transparencia en la administración pública chilena: Inevitable y deseable ponderación». En Varios autores, Reflexiones sobre el uso y abuso de los datos personales en Chile. Santiago: Expansiva.

\section{SOBRE EL AUTOR}

Francisco Alvarado Ávalos es abogado. Licenciado en Ciencias Jurídicas y Sociales de la Facultad de Derecho de la Universidad de Chile. El presente artículo es una versión parcial de su memoria para optar al grado de Licenciado en Ciencias Jurídicas y Sociales. Su correo electrónico es < francisco_d_alvarado@hotmail.com> y su dirección postal es Los Talaveras 579, Nuñoa.

Este trabajo fue recibido el 6 de octubre de 20 I 4 y aprobado el I I de diciembre de 2014 . 